\title{
THE GAY MEN SEX STUDIES: DESIGN OF AN ONLINE REGISTRATION OF SEXUAL BEHAVIOUR OF MEN HAVING SEX WITH MEN AND PRELIMINARY RESULTS (GAMESSS-STUDY)
}

\author{
Johan Vansintejan, Jan Vandevoorde, Dirk Devroey \\ Department of Family Medicine, Vrije Universiteit Brussels (VUB), Brussels, Belgium
}

\section{SUMMARY}

Background: There has been limited investigation of the sexuality and sexual dysfunction in homosexuals by the sexual medicine community. The purpose of this article is to describe the methodology of the online GAy MEn Sex StudieS (GAMESSS) on the sexual behaviour and sexual dysfunctions of Belgian men who have sex with men (MSM).

Aim: To describe the methodology of an online study that investigate sexual behaviour and sexual function and dysfunction in a sample of Belgian MSM.

Methods: An internet-based survey on sexual behaviour and sexual dysfunctions was administered to MSM between April and December 2008. The questionnaire was a compilation of the Kinsey Scale for Sexual Orientation, the Index of Premature Ejaculation (IPE), the Erection Quality Scale (EQS), the Female Sexual Function Index (FSFI), the Brief (Male) Sexual Function Inventory (BSFI) and the Gay Men Sexual Addiction Screening Test (G-SAST). The analytic sample comprised 1,830 Belgian men aged 18 years or older, who reported having sex with men.

Conclusion: The use of an online questionnaire is a convenient way to gather information from a hidden population such as MSM. The anonymity of the participants is guaranteed. The collected data can be easily analyzed. With this online study, we aim to detect variables in sexual behaviour (SB) and sexual dysfunction (SD) that can help to improve care for MSM. Belgian MSM have a very active and varied sex life. They are rather promiscuous and do not always practice safe sex. This behaviour poses a high risk of spreading sexually transmitted diseases. Additional research in this MSM population is needed.

Key words: homosexuality, bisexuality, internet, sexual behaviour, sexual dysfunction

Address for correspondence: J. Vansintejan, Department of Family Medicine, University of Brussels (VUB), Laarbeeklaan 103, B-1090 Brussels, Belgium. E-mail: johan.vansintejan@vub.ac.be

\section{INTRODUCTION}

The worldwide expansion of access to and use of the internet over the last two decades has made the World Wide Web a prominent mode of communication. Nowadays, the internet is being recognized as a research tool to conduct quantitative and qualitative research. Internet-based data collection is receiving increasing attention in the social and health sciences (1). Data from the National Institute of Statistics (NIS) shows that Belgium had 2.81 million internet connections in the last quarter of 2008. These figures relate to most, but not all Belgian internet providers. The number of connections does not necessarily match the number of users. One connection can be used by different users and one user can have access to different connections. About $71 \%$ of households in Belgium have one or more computers. In $2009,67 \%$ had access to the internet. In the European context, Belgium is an average performer, before France (63\%), but behind Germany (79\%), and the Netherlands, the European frontrunner with $90 \%$ of the households connected to the internet. It also appears that the group of users is still increasing. Nowadays, there are 3,28 million internet connections in Belgium. The quick rise of the internet use opens new areas for social science researchers to investigate.
Homosexuals are a hidden population. The measurement of prevalence and incidence of sexual activity and sexual dysfunctions in sub-populations such as men who have sex with men (MSM) is hampered by the unknown size and regional distribution of this "hidden" population. First of all, MSM are not at sight distinguishable from heterosexuals and there is no "list of all gay people in Belgium". Taking a random sample is impossible. Gays are not a homogeneous group. They are men and women, young and old, individuals from lower and higher socio-economic classes. They do not necessarily identify with the stereotypical images of gay life or the gay community. MSM do not all experience their sexuality in the same way. MSM have a wide variation in sexual techniques to satisfy themselves and their partner(s). Not all MSM practice anal sex, some only prefer masturbation and/or oral sex. Some expose their sexual orientation in their way of clothing; others are still living "in the closet". They can even be married to a woman and have a sexual relationship with another man.

Homosexual men have received limited attention in the sexual medicine literature despite constituting a substantial minority of population (estimated at 4-5\%) (2). Non-heterosexual orientation is usually an exclusion criterion in many large scale studies in sexual medicine $(3,4)$. Furthermore, the majority of instruments 
for the assessment of sexual dysfunction have not been validated in homosexual patients and use heterosexually-oriented language; for instance, sexual penetration or sexual intercourse is defined as the introduction of the penis inside the vagina not into the anus. The focus of most published research was on sexual behaviour (SB) and sexual dysfunction (SD) in the context of HIV transmission risk (5).

An internet-based survey of 7,001 U.S. MSM, recruited in 2004-2005 from gay-oriented sexual networking, chat and news websites found that $79 \%$ of men reported one or more sexual dysfunction symptoms. The most common problems were low sexual desire, erectile dysfunction and performance anxiety (6).

The Department of Experimental Psychology (Faculty of Psychology, University of Maastricht) launched in 2002 an internet research on "chat", dating and sex among gay men. Through the site, the researchers reached a large number of respondents in a short time (12,000 visitors in 26 days). Compared with previous research, certain subgroups were better reached. There were significantly more MSM younger than 25 years, more ethnic minority gays, more gays with a lower education, and more MSM who were still "in the closet". The number of bisexuals was significantly higher in this survey than in other studies (7). Additional research in the MSM population is needed. In this paper, we describe the design of the online registration that investigates SB and SD in a sample of Belgian MSM. Afterwards, we can compare these results with studies on a heterosexual population or with a MSM population from other countries.

\section{MATERIALS AND METHODS}

\section{Study Design}

The GAy MEn Sex StudieS (GAMESSS) combined several comprehensive structured questionnaires that investigate several areas of male sexual experience. Both gay-targeted and general topics are covered. The website included an introduction to the study and the aims of the research. The questionnaire contains following items: socio-demographic data, sexual experience, getting erection, orgasm experience, experience of anal sex, and sex addiction. Internationally used and validated questionnaires were grouped into one online survey. The Kinsey Scale for Sexual Orientation (8) was used to determine if the participants identify themselves as heterosexual, bisexual or homosexual. The Index of Premature Ejaculation (IPE) could detect problems of ejaculation (9). For the detection of erectile dysfunction the Erection Quality Scale (EQS) (10) was used instead of the widely used International Index of Erectile Function (IIEF) (11), because the questionnaire of EQS is applicable to single, heterosexual and homosexual men. The Female Sexual Function Index (FSFI) (12) evaluated the possibility of having pain during sexual activity. We used it to detect pain during or after anal intercourse. The Brief (Male) Sexual Function Inventory (BSFI) (13) is a brief and discrete screening instrument for assessing sexual function and sexual satisfaction. The Gay Men Sexual Addiction Screening Test (G-SAST) (14, 15 ) is especially developed to detect sexual addiction among gay men. The questionnaire was available in three languages: Dutch, French and English. For translations into Dutch and French the forward/backward method was used.
The questionnaire was presented in a respondent-friendly way, mostly as multiple choice questions. Participants had to indicate the most corresponding answer. For most questions answering was mandatory in order to continue the survey. Only when they indicated not having used PDE 5 inhibitors for erectile dysfunction, 3 questions concerning the use of the substances were skipped.

In total, the questionnaire consisted of 90 questions. It takes a considerable effort of about 20 minutes to complete, which increases the possibility that participants will abandon the survey prematurely. Visitors of the website were motivated to participate and complete all the questions correctly. Therefore, the activation of intrinsic and extrinsic motivation of respondents was used. We pointed out the importance of this survey to improve equal opportunities policy on gays. It was an extensive questionnaire and to prevent participants abandoning it too quickly, we included a "teasing" factor. A tasteful black and white non-explicit photograph of one or two male nudes in various positions was added on each web-page. This stimulates the curiosity of the participants to continue the questionnaire.

\section{In- and Exclusion Criteria for Participant Selection}

Participants were required to be $\geq 18$ years of age. Exclusion criteria were: women, men under the age of 18 years and men who have an exclusive sexual relationship with women. The participants who indicated being heterosexuals on the Kinsey Scale for Sexual Orientation were excluded (8). We restricted our population to a sample of the Belgian MSM. Participants from outside Belgium were filtered out.

\section{Data Collection}

The URL address for the website was http://www.gamesss.be. A press release about the launch of this major investigation was sent to both audiovisual media and paper press. Participants were recruited by references to the website in various media and by the distribution of 25,000 flyers, with a condom attached, targeting the gay visitors of parades and meeting places. Links to the survey were posted on the websites of most gay organizations and a number of commercial gay-oriented websites, as shown in Table 1.

The registration period was from April 2008 till December 2008. Participation in this survey was voluntary and anonymous, and the privacy of the participants was guaranteed.

\section{Baseline Measurements}

Data for the GAMESSS study were collected entirely via the internet. Before entering the online survey, participants have to confirm to belong to the male gender. At that time, a registration number (ID), an unique identifier (UID), and the date and the time of registration were recorded.

The ID is simply an arithmetic sequence in the database. The UID is a random number between 150000 and 999999999999 used in a cookie on the client side that identifies the data from the participant on the server side and guarantees that the information is written in his record in the database. This UID is stored in a cookie on the computer of the participant during registration. The cookie is automatically erased when the participant is at 
Table 1.

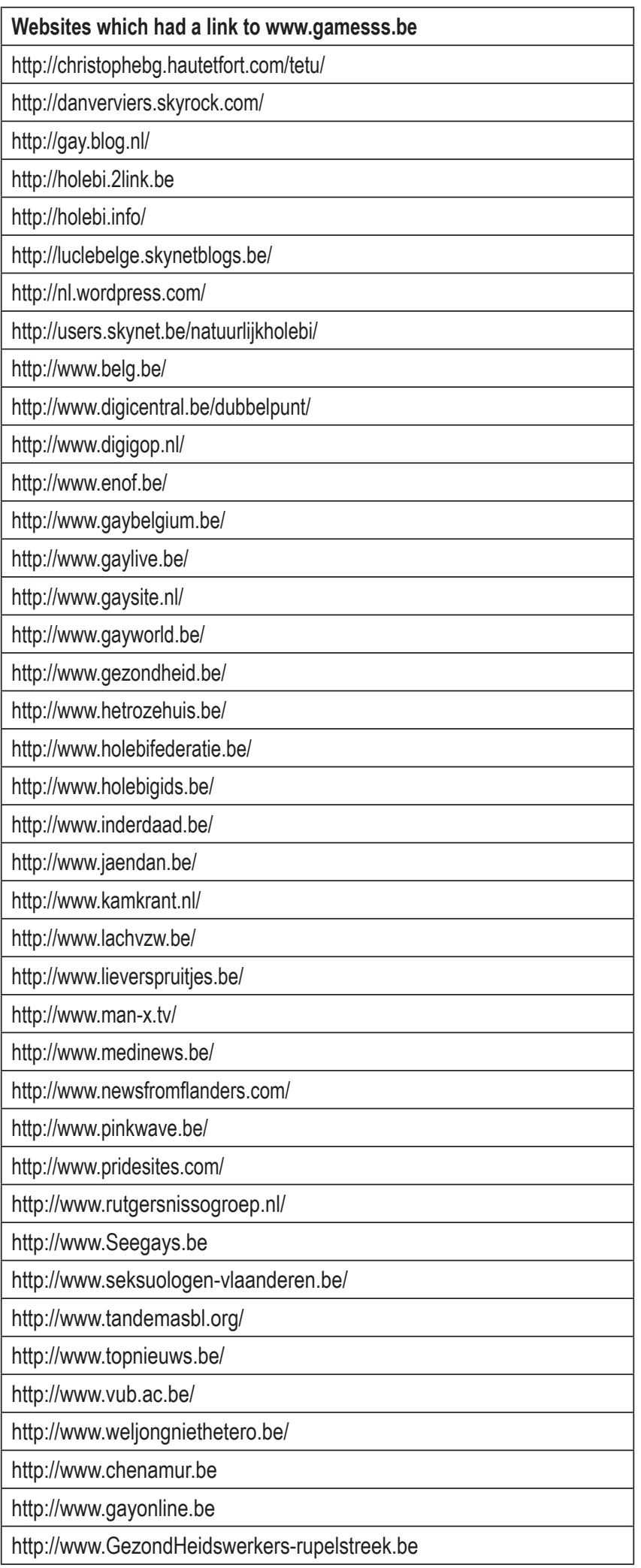

the end of the questionnaire or after 2 hours if the participant is not at the end of the questionnaire. The use of such a cookie with the UID is necessary. Firstly, because several participants may be including data simultaneously, and secondly, because it prevents the storing of data of people who want to include multiple faked data.
Date and time are not strictly necessary for the analysis of the data, but rather a monitoring of the evolution of the number of registrations. At no time, the IP address or other personal data from the computer of the participants were registered. All data are stored in a MySQL database. The data can only be consulted through a secure web page with an Apache security login and password.

\section{Data Management and Statistical Analysis}

The data of this study were entered into an online registration system by the participants themselves. Databases were stored with a central data manager at the Faculty of Medicine and Pharmacy of the University of Brussels. Several control measures ensured data quality and limited missing data by repeating some multiple choice questions with the possible answers in a different order. Data cleaning and data analyses for this study were performed using IBM SPSS Statistics 19.0.0 (SPPS Inc., Chicago, IL, USA).

Data cleaning was performed in two steps: detection of errors in the dataset and correction of these errors. The data cleaning looked for missing data, typing errors on data entry, column shift on data entry, coding errors, systematic repetitive answers, discordant answers and errors related to misinterpretation of questions. Errors were detected by using descriptive statistics, scatter plots and histograms. The presence of systematic repetitive answers was considered when the same option was systematically selected in consecutive questions.

Univariate association between parameters was tested by means of the standard Pearson chi square tests. The Fisher exact test was used when less than 10 observations were concerned. The independent-samples t-test was used to compare continuous variables. Multivariate analyses were performed with backward stepwise logistic regression.

\section{Primary and Secondary Outcome Measures}

We aim to explore SB and SD of Belgian MSM by finding the answers to the following questions. How do MSM experience their sex-life. What is the prevalence of libido disorders, erectile dysfunction, orgasmic problems, anal dyspareunia and sex addiction among Belgian MSM? Is there a difference in the prevalence of SD between the heterosexual population and MSM? Is there a difference in the prevalence of SD between Belgian and foreign MSM? Does the knowledge of HIV status have an influence on SB of MSM? In addition, we aim to evaluate the use of PDE 5 inhibitors or other drugs to improve erection by MSM.

\section{Privacy Protection and Ethical Approval}

The anonymous patient data were treated with the utmost discretion. The online registration system did not permit to analyze data from individual patients. The study-protocol was approved by the Ethical Committee of the University Hospital of Brussels.

\section{Characteristics of the Participants}

At the end of the registration period, 4,006 persons had started the online survey. With a drop-out of 39\%, 2,438 participants had fully completed the questionnaire. The large amount of drop-outs may be caused by the number of questions. The participants could follow their progression throughout the whole questionnaire by 
a visual bar and a percentage of completion. The majority of the drop-outs stopped answering quickly after the first questions of language and gender. After clicking four times to go to the next page and the next question, they saw they had completed only $1 \%$ of the questionnaire.

Of the 2,438 participants who had finished the test, a majority of $76 \%$ had the Belgian nationality. Only $2 \%$ used the English questionnaire, $26 \%$ the French and $72 \%$ were Dutch speaking. By using the Kinsey Scale for Sexual Orientation (8), 13 heterosexual men were excluded. Our study population was fixed at 1,830 Belgian MSM. The majority of the respondents live in the northern (Dutch-speaking) part of the country (Fig. 1). Most of the participants are living in big cities, such as Gent, Antwerp, Brussels, and Liege.

The mean age of all respondents was 35 years $( \pm 12$ SD). Table 2 shows the characteristics of the study population. The average age of their first sexual experience with the same-sex partner was 19 years. The first sexual partner was usually 4 years older. Almost $57 \%$ declared to have a steady relationship. Of all respondents, $65 \%$ had more than 50 sexual partners, and even one in four has had sex with more than 100 different men. Among the responders, $48 \%$ declared they had sex sometimes with more than two other men at the same time, and even $10 \%$ with more than 10 other men. In the study population, 78 men (4\%) declared being HIV

Table 2. Characteristics of the study population $(n=1830)$

\begin{tabular}{|c|c|c|}
\hline \multicolumn{3}{|l|}{ Age groups } \\
\hline$<29$ years & 706 & $38.6 \%$ \\
\hline 30-39 years & 522 & $28.5 \%$ \\
\hline 40-49 years & 358 & $19.6 \%$ \\
\hline $50-59$ years & 187 & $10.2 \%$ \\
\hline$>60$ years & 57 & $3.1 \%$ \\
\hline \multicolumn{3}{|l|}{ Highest level of education } \\
\hline Primary school & 30 & $1.6 \%$ \\
\hline Lower secondary school & 80 & $4.4 \%$ \\
\hline Higher secondary school & 452 & $24.7 \%$ \\
\hline Higher education short course & 430 & $23.5 \%$ \\
\hline Higher education long course & 217 & $11.9 \%$ \\
\hline University & 438 & $23.9 \%$ \\
\hline Post-university & 156 & $8.5 \%$ \\
\hline Other education & 27 & $1.5 \%$ \\
\hline \multicolumn{3}{|l|}{ Relationship } \\
\hline No steady relationship & 793 & $43.3 \%$ \\
\hline Open steady relationship & 503 & $27.5 \%$ \\
\hline Closed steady relationship & 534 & $29.2 \%$ \\
\hline \multicolumn{3}{|l|}{ Sex role } \\
\hline Active & 191 & $10.4 \%$ \\
\hline Versatile & 1516 & $82.9 \%$ \\
\hline Passive & 123 & $6.7 \%$ \\
\hline
\end{tabular}

\begin{tabular}{|c|c|c|}
\hline \multicolumn{3}{|c|}{ Number of sex partners in their lifetime } \\
\hline None (never had sex with a man) & 24 & $1.4 \%$ \\
\hline 1 & 73 & $4.0 \%$ \\
\hline 2 to 5 men & 294 & $16.1 \%$ \\
\hline 6 to 10 men & 252 & $13.8 \%$ \\
\hline 11 to 50 men & 503 & $27.5 \%$ \\
\hline 51 to 100 men & 242 & $13.2 \%$ \\
\hline 101 to 500 men & 300 & $16.4 \%$ \\
\hline$>500$ men & 142 & $7.8 \%$ \\
\hline \multicolumn{3}{|c|}{ Number of sex partners at the same time } \\
\hline None (never had sex with a man) & 47 & $2.6 \%$ \\
\hline 1 man & 517 & $28.3 \%$ \\
\hline 2 men & 376 & $20.5 \%$ \\
\hline 3 men & 219 & $12.0 \%$ \\
\hline 4 or 5 men & 306 & $16.7 \%$ \\
\hline Between 6 and 10 men & 172 & $9.4 \%$ \\
\hline$>10$ men & 193 & $10.5 \%$ \\
\hline \multicolumn{3}{|l|}{ Frequency of masturbation } \\
\hline Never & 9 & $0.5 \%$ \\
\hline Less than once a month & 41 & $2.2 \%$ \\
\hline 1 to 3 times a month & 129 & $7.0 \%$ \\
\hline 1 to 3 times a week & 779 & $42.6 \%$ \\
\hline Daily & 683 & $37.3 \%$ \\
\hline More than once a day & 189 & $10.3 \%$ \\
\hline \multicolumn{3}{|c|}{ Frequency of sexual intercourse with a men } \\
\hline Never & 53 & $2.9 \%$ \\
\hline Less than once a month & 195 & $10.7 \%$ \\
\hline 1 to 3 times a month & 376 & $20.5 \%$ \\
\hline 1 or 2 times a week & 652 & $35.6 \%$ \\
\hline At least 3 times a week & 406 & $22.2 \%$ \\
\hline Daily & 111 & $6.1 \%$ \\
\hline More than once a day & 37 & $2.0 \%$ \\
\hline
\end{tabular}


Table 3. Distribution of the respondents by age

\begin{tabular}{|l|c|c|c|c|c|}
\hline Age-group & $<\mathbf{2 6}$ years & $\mathbf{2 6 - 3 9}$ years & $\mathbf{4 0 - 5 4}$ years & $>\mathbf{5 5}$ years & Total \\
\hline Number of respondents & $462(25 \%)$ & $815(45 \%)$ & $\mathbf{4 4 3}(24 \%)$ & $110(6 \%)$ & $1830(100 \%)$ \\
\hline Steady relationship in each age-group & $50 \%$ & $60 \%$ & $59 \%$ & $54 \%$ & $57 \%$ \\
\hline Sex outside their steady relationship in each age-group & $15 \%$ & $41 \%$ & $53 \%$ & $56 \%$ & $38 \%$ \\
\hline Infected with HIV & $5(1 \%)$ & $31(4 \%)$ & $36(8 \%)$ & $6(5 \%)$ & $78(4 \%)$ \\
\hline
\end{tabular}

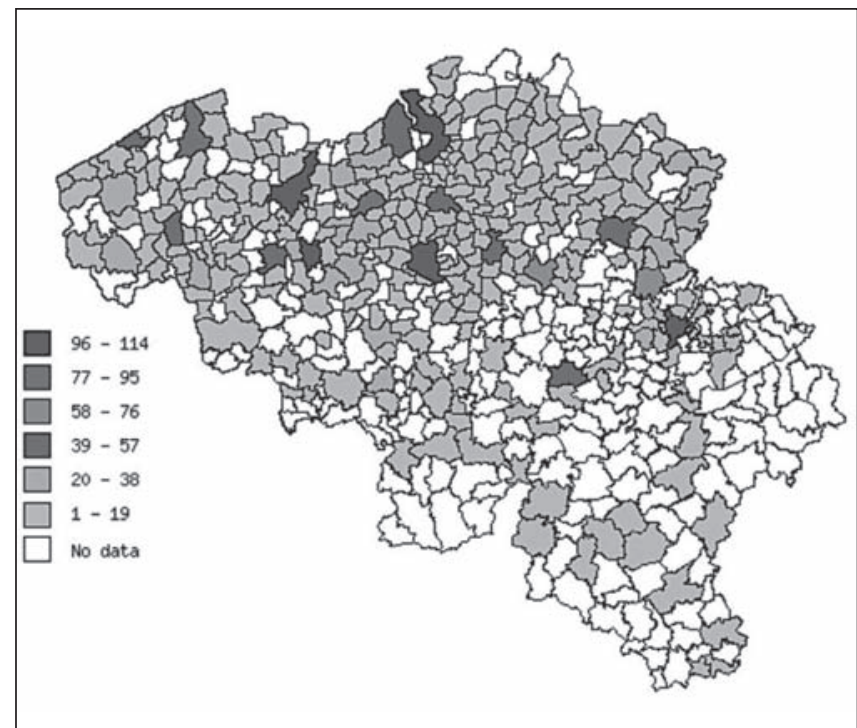

Fig. 1. Demographic distribution of the Belgian participants.

positive. In 2008, 743 men were diagnosed with HIV infection in Belgium; among them 64\% acquired the infection through homosexual contact (16).

\section{Sexual Behaviour}

Although Belgian MSM have sex with a male partner on average two times a week, they also practice masturbation daily until the age of 33 years. This frequency decreases gradually with age. MSM older than 55 years still masturbate every three days and only $2 \%$ of them had no sexual relationship anymore. They also take time to satisfy each other sexually, because lovemaking takes about 49 minutes (fore- and after-play included). The older MSM get, the more they have sex outside their relationship. Above the age of 40 years, more than half of the couples have sex with another man besides their own partner. A majority of $82 \%$ practice gay sex being both active and passive. They enjoyed penetrating their partner as well as being penetrated during anal intercourse. When we asked which sex technique was the most pleasurable on a scale from 0 (no experience) to 10 (the most pleasurable), getting oral sex was listed on the first place, followed by giving the partner oral sex. On the third place came masturbate himself and number four was being masturbated by the partner. Although $30 \%$ of respondents did not have anal sex, practicing anal sex actively, meaning penetrating their partner's anus, ended on the fifth place. This was not always done safely, because $28 \%$ reported not using a condom for anal penetration. The least pleasurable sex techniques were oral-anal sex and sadomasochism.

\section{DISCUSSION}

The anonymity of the internet means for many gay men a new way to get to know other gays and lesbians. Mainly for MSM, the internet has become an important source of dating. In Western post-industrialized countries, asking people about their sexual preferences is becoming more and more acceptable. In computerassisted interviews, anonymous respondents are more willing to answer sensitive questions, such as on sexual preferences, than in person-to-person interviews.

Among the other benefits of e-research, we must highlight the possibility to make some questions 'obligatory' to answer and the ability to filter issues (a section of the questionnaire can be skipped when this is not relevant to the particular respondent taking into account his previous answers). A disadvantage of e-research is that men without access to the internet could not participate. Because older people have less access to the internet, older MSM are likely to be underrepresented. The design of the site, the maintenance of the pool of respondents and so on takes much time. Once this preparatory phase is over, however, the data collection runs very fast and can be easily analyzed. This methodology was already used for the European MSM Internet Survey (EMIS) in 2010 and other HIV surveillance studies (17-19).

Prejudice and discrimination, both on a personal and social level create difficulties in designing a representative sample of hidden populations. These problems particularly emerge when trying to identify certain subgroups within that population, for instance, the patients with HIV infection. In the past, there was always a representation problem proved to gay studies. Not all groups based on age, gender and education within the gay population were equally represented. Older gays, lesbians, and less educated people were less represented. The use of particular approach will therefore depend on the purpose, subject matter and the sources of the project. The combination of different techniques helps to ensure diversity within the sample.

More and more research on sexual health is done not only among HIV+ patients but in the general and MSM population. We compared our results with a Dutch survey "Sexual Health in the Netherlands 2011" consisting of a sample of 3,972 heterosexual men (aged between 15 and 70 years) (20). The mean age for the first sexual experience was 18 years for the Dutch heterosexuals, and 19 years for the Belgian MSM. Two-thirds of the MSM population and $54 \%$ of the heterosexuals mentioned having sexual intercourse with a partner at least once a week. MSM masturbated more frequently: $99.5 \%$ of MSM vs. $83 \%$ of the Dutch heterosexuals. Anal sex was performed by $30 \%$ of the heterosexuals and $70 \%$ of MSM. In these groups, $48 \%$ of the heterosexuals and $28 \%$ of MSM did not use a condom for having anal intercourse. Both groups are at high risk of contracting HIV 
or another sexually transmitted diseases (STD). More campaigns on prevention of STD must be necessarily conducted.

\section{CONCLUSION}

The use of an online questionnaire is a convenient way to gather information from a hidden population. The anonymity of the participants is guaranteed. There is no direct face to face contact between the researchers and the volunteers. Nowadays, more and more research is done via the internet. The collected data can be easily analyzed. With this online study, we aim to detect variables in SB and SD that can help to improve the care for MSM. Belgian MSM have a very active and varied sex life. They are rather promiscuous and do not always practice safe sex. This behaviour poses a high risk of spreading sexually transmitted diseases.

\section{Acknowledgements}

The authors thank all participating men for the registration.

\section{Conflict of Interest}

None declared

\section{Ethical Approval}

The study protocol was approved by the Ethical committee of the University Hospital of Brussels.

\section{Funding}

The study was not funded by an external organisation. The condoms for the promotion of the study were provided by LSE Holland.

\section{REFERENCES}

1. Tates K, Zwaanswijk M, Otten R, van Dulmen S, Hoogerbrugge PM, Kamps WA, et al. Online focus groups as a tool to collect data in hardto-include populations: examples from paediatric oncology. BMC Med Res Methodol. 2009 Mar 3;9:15.

2. Breyer BN, Smith JF, Eisenberg ML, Ando KA, Rowen TS, Shindel AW. The impact of sexual orientation on sexuality and sexual practices in North American medical students. J Sex Med. 2010;7(7):2391-400.

3. Goldstein I, Lue TF, Padma-Nathan H, Rosen RC, Steers WD, Wicker PA; Sildenafil Study Group. Oral sildenafil in the treatment of erectile dysfunction. N Engl J Med. 1998 May 14;338(20):1397-404. Erratum in: N Engl J Med. 1998 Jul 2;339(1):59.
4. Rendell MS, Rajfer J, Wicker PA, Smith MD; Sildenafil Diabetes Study Group. Sildenafil for treatment of erectile dysfunction in men with diabetes: a randomized controlled trial. JAMA. 1999 Feb 3;281(5):421-6.

5. Sandfort TG, de Keizer M. Sexual problems in gay men: an overview of empirical research. Annu Rev Sex Res. 2001;12:93-120.

6. Hirshfield S, Chiasson MA, Wagmiller RL Jr, Remien RH, Humberstone M, Scheinmann R, et al. Sexual dysfunction in an Internet sample of U.S. men who have sex with men. J Sex Med. 2010 Sep;7(9):3104-14.

7. Hospers HJ, Kok G, Harterink P, de Zwart O. A new meeting place: chatting on the Internet, e-dating and sexual risk behaviour among Dutch men who have sex with men. AIDS. 2005 Jul 1;19(10):1097-101.

8. Kinsey AC, Pomeroy WR, Martin CE. Sexual behavior in the human male. 1948. Am J Public Health. 2003 Jun;93(6):894-8.

9. Althof S, Rosen R, Symonds T, Mundayat R, May K, Abraham L. Development and validation of a new questionnaire to assess sexual satisfaction, control, and distress associated with premature ejaculation. J Sex Med. 2006 May;3(3):465-75.

10. Wincze J, Rosen R, Carson C, Korenman S, Niederberger C, Sadovsky $\mathrm{R}$, et al. Erection quality scale: initial scale development and validation. Urology. 2004 Aug;64(2):351-6.

11. Rosen RC, Riley A, Wagner G, Osterloh IH, Kirkpatrick J, Mishra A. The international index of erectile function (IIEF): a multidimensional scale for assessment of erectile dysfunction. Urology. 1997 Jun;49(6):822-30.

12. Isidori AM, Pozza C, Esposito K, Giugliano D, Morano S, Vignozzi L, et al. Development and validation of a 6-item version of the female sexual function index (FSFI) as a diagnostic tool for female sexual dysfunction. J Sex Med. 2010 Mar;7(3):1139-46.

13. Mykletun A, Dahl AA, O'Leary MP, Fosså SD. Assessment of male sexual function by the Brief Sexual Function Inventory. BJU Int. 2006 Feb;97(2):316-23.

14. Carnes PJ. Sexual addiction and compulsion: recognition, treatment, and recovery. CNS Spectr. 2000 Oct;5(10):63-72.

15. Carnes P. Sexual addiction screening test. Tenn Nurse. 1991 Jun;54(3):29.

16. Sasse A, Verbrugge R, Van Berckhoven D. Epidemiology of AIDS and HIV infection in Belgium. Brussels: The Scientific Institute of Public Health (WIV-ISP); 2011.

17. Berg RC, Ross MW, Weatherburn P, Schmidt AJ. Structural and environmental factors are associated with internalised homonegativity in men who have sex with men: findings from the European MSM Internet Survey (EMIS) in 38 countries. Soc Sci Med. 2013 Feb;78:61-9.

18. Marcus U, Hickson F, Weatherburn P, Schmidt AJ; EMIS Network. Prevalence of HIV among MSM in Europe: comparison of self-reported diagnoses from a large scale internet survey and existing national estimates. BMC Public Health. 2012 Nov 14;12(1):978.

19. Thériault N, Bi P, Hiller JE, Nor M. Use of web 2.0 to recruit Australian gay men to an online HIV/AIDS survey. J Med Internet Res. 2012 Nov 6;14(6):e149.

20. de Graaf $\mathrm{H}$. Sexual behaviour and feelings in the Netherlands. Tijdschrift voor seksuologie. 2012 Mar;36(2):87-97. (In Dutch.) 